\author{
С. А. Крылов \\ Институт востоковедения РАН \\ (Россия, Москва) \\ krylov-58@mail.ru
}

\title{
К ВОПРОСУ О РАЗЛИЧЕНИИ ПОВЕРХНОСТНОЙ И ГЛУБИННОЙ СЕМАНТИКИ*
}

Цель настоящей статьи - предварительно очертить некоторый подход, при котором в семантике различаются четыре «уровня» глубины, а также попытаться классифицировать лингвистические дисциплины (прежде всего разделы современной семантики) в соответствии с этим «четырехуровневым» подходом. Означающее и означаемое связаны друг с другом прямо, т.е. непосредственно. Их взаимно-однозначное соответствие нарушается только при морфологической эквивалентности (полиморфности, т. е. омосемии и дублетности) и амбивалентности (омонимии). Означаемое и значение связаны «асимметричной связью», включающей, кроме прямой номинации (и основного значения), также отклонения от него, а именно инвентарно-семантическую эквивалентность (языковую синонимию) и инвентарно-семантическую амбивалентность (языковую полисемию). Значения и означаемые (так же, как и означающие) принадлежат языковой системе, они хранятся в долговременной памяти, их количество можно подсчитать. Их можно перечислить в инвентаре (лексиконе или грамматиконе). Содержания и смыслы принадлежат речи, они хранятся в кратковременной памяти, их перечислить невозможно, но зато они формируются по определенным интегрально-семантическим и прагматическим правилам, поэтому их можно вычислить. Схематически выделяются такие разделы семантики: тривиальная (она изучает отношения между означающим и означаемым), инвентарная (она изучает отношения между означаемым и значением), интегральная (она изучает отношения между значением и содержанием) и прагматическая (она изучает отношения между содержанием и смыслом; = прагматика). Независимо от этого деления семантика делится на семантику

* Работа выполнена при частичной поддержке грантов РФФИ № 1704 00594-ОГН ОГНА «Автоматический словарь РУСЛАН: обновленная концепция, новая лексика», РФФИ № 1801200650 А «Семантические категории в грамматическом строе РЯ», РФФИ № 17-29-02305 и РФФИ № 17-29-09158 офи_м «Создание корпуса официально-деловых текстов РЯ (ОДКРЯ)». 
говорящего и семантику слушающего, поэтому внутри инвентарной семантики выделяются семасиология vs. ономасиология, внутри интегральной — интерпретирующая vs. порождающая семантика, внутри прагматической - герменевтика и риторика. Моделированием понимания (речевосприятия) заняты семасиология, интерпретирующая семантика (= модель семантического анализа) и герменевтика (= модель прагматического анализа). Моделированием говорения (речепорождения) заняты ономасиология, порождающая семантика (= модель семантического синтеза) и риторика (= модель прагматического синтеза).

Ключевые слова: семантика, значение, означаемое, смысл, содержание, прагматика, анализ, синтез, семасиология, ономасиология.

1. Одной из тем, уже много лет привлекавших внимание Ю.Д. Апресяна, является тема различения в семантике нескольких разных уровней глубины.

2. Цель настоящей статьи - предварительно очертить некоторый подход, при котором в семантике различаются четыре «уровня» глубины, а также попытаться классифицировать лингвистические дисциплины (прежде всего разделы современной семантики) в соответствии с этим «четырехуровневым» подходом.

3. К моделированию понимания возможен подход, при котором различается ряд уровней на «оси обозначения» ${ }^{1}$, связывающей «поверхностные» сущности с «глубинными» ${ }^{2}$.

Идея расслоения содержательной стороны языка на ряд уровней разделяется многими теоретиками семантики - как в XIX в. ${ }^{3}$, так и в XX в. ${ }^{4}$

4. Один из возможных подходов к уровням глубины понимания речевого отрезка таков. Предлагается различать четыре уровня понимания, соответственно, четыре уровня плана содержания речевых отрезков (т. е. их «внутренней» стороны). Эти четыре уровня «информации» (// «содержания», в самом широком смысле слова) можно или пронумеровать, или (с небольшой «натяжкой») предложить для каждого из них подходящий термин.

4.1. Для обозначения внутренней стороны инвентарных единиц языка (т. е. для обозначения инвентарных семантических единиц) обычно используется термин значение (в широком смысле слова). Но для более тонкой дифференциации полезно договориться о более узком употреблении терминов.

4.1.1. Означаемое (// десигнат, иногда оно называется общзее // системное значение).

${ }^{1}$ В терминах 3. М. Шаляпиной.

${ }^{2}$ Ср. идеи Ю.С. Мартемьянова, С. Лэма, У. Л. Чейфа, А.К. Жолковского и И. А. Мельчука, В.Г. Гака, Ю. Д. Апресяна, Е. В. Падучевой и других теоретиков семантики, идею «уровней эквивалентности» при переводе (В. Г. Гак, В.Н. Комиссаров, А. Д. Швейцер).

${ }^{3}$ См. работы В. Гумбольдта, А. А. Потебни, Г. Пауля.

${ }^{4}$ См. работы Л.С. Выготского, В. Матезиуса, Э. Кошмидера, А. Гардинера, В.Н. Волошинова, В. Скалички, Э. Косериу, Н. И. Жинкина, С. Д. Кацнельсона, В. А. Звегинцева, П. Сгалла, П. Адамца, Г. П. Мельникова, Г. П. Щедровицкого, А. А. Леонтьева, Н. А. Слюсаревой, Б. М. Лейкиной, Т. В. Булыгиной, А.В. Бондарко, И. М. Кобозевой и др. 
4.1.2. (Собственно) значение (// сигнификат, иногда оно называется частное // узуальное значение).

Означаемые, как и значения, суть инвентарные единицы: они принадлежат языковой системе (инвентарю), поэтому их в принципе можно задать конечным списком. Хотя этот список будет небольшим (и ограниченным, т. е. «закрытым») лишь для грамматических значений; а список лексических значений в языке огромен (и практически неограничен, т. е. «открыт»), но все же его можно описать хотя бы с некоторой степенью приближения как конечное множество (так, эти степени будут разными в «карманном», «учебном», «практическом (однотомном)» и «академическом (многотомном)» словарях). Этим единицы первого и второго уровней («инвентаризуемые семантемы», по И. П. Сусову) принципиально отличаются от единиц (или «комбинаций единиц») третьего и четвертого уровней.

Отличие между означаемыми и значениями давно известно лингвистике под именем различения «общих» и «частных» значений (в важности этого различения, впрочем, сомневались многие теоретики: только одни из этих скептиков отрицали существование «общих значений», а другие, напротив, отрицали существование «частных значений»).

Языковых знаков (в «соссюровском» смысле) столько же, сколько означаемых. Совпадение экспонентов у языковых знаков с разными означаемыми есть омонимия; совпадение означаемых у знаков с разными экспонентами есть абсолютная (полная) «синонимия», «дублетность» или «омосемия». Совпадение означаемого со значением возможно лишь при моносемии (чаще всего у терминов). Так как большинство языковых знаков полисемичны, то обычно одно означаемое состоит из нескольких значений.

4.2. Для обозначения внутренней стороны экстраинвентарных (комбинаторных, конструируемых) языковых единиц (т. е. для обозначения экстраинвентарных семантических единиц) обычно используется термин смысл (в расширенном употреблении) [см., например: Слюсарева 1963; Звегинцев 1973; Швейцер 1988: 114-118; Кобозева 2000а: 8-15; 2000б: 303-359]. Но для более тонкой дифференциации полезно договориться о более узком употреблении терминов.

4.2.3. (Собственно) содержание (иногда оно называется контекстное // контекстуальное значение).

4.2.4. (Собственно) смысл (иногда оно называется окказиональное // актуальное значение).

Договоримся для краткости ниже называть единицы этих четырех уровней означаемыми (4.1.1), значениями (4.1.2), содержаниями (4.2.3) и смыслами (4.2.4).

5. Четырехуровневая модель понимания речевых отрезков.

5.1. Первый, примитивный, уровень понимания речевых отрезков - это понимание с точностью до означаемых: омонимия (как грамматическая, так и лексическая) уже «снята», но полисемия еще «не снята». Такой уровень понимания, видимо, обладает некоторой степенью психологической реальности.

5.2. Второй, более тонкий, уровень понимания речевого отрезка - это понимание с точностью до значений: снята не только омонимия, но и «языковая» 
полисемия языковых знаков, входящих в этот речевой отрезок. Этот уровень обладает некоторой степенью психологической реальности.

Меру этой реальности можно оценить степенью единодушия между лингвистами, описывающими набор «отдельных значений» многозначной лексической единицы в словаре или набор потенциальных «частных значений», присущих той или иной граммеме некоторой грамматической категории; а наличие некоторых разногласий между лингвистами свидетельствует лишь о диффузности самой границы между «инвентарными» значениями и внеинвентарными (окказиональными) употреблениями. Кроме того, эта граница является «зыбкой» по принципиальным причинам: язык изменчив по природе, и окказиональные употребления на наших глазах переходят в узуальные значения. Внимание, уделяемое проблемам репрезентации высказывания на втором уровне понимания (не говоря уже о более глубоких уровнях), в работах по АОТ пока что было практически минимальным.

5.3. Третий, еще более глубокий, уровень понимания речевого отрезка - это его понимание с точностью до содержания этого речевого отрезка, т.е. результат применения к его значению (т. е. к репрезентации, фиксирующей те входящие в инвентарь данного языка «частные» значения языковых знаков, входящих в данный речевой отрезок, в которых эти языковые знаки употреблены) всевозможных «правил взаимодействия значений», при помощи которых из «инвентарных» значений создаются их внеинвентарные (контекстуальные) интерпретации.

5.4. Четвертый, наиболее глубокий, «прагматический» уровень понимания речевого отрезка - это понимание его смысла. Смысл речевого отрезка есть результат применения к его содержанию некоторого ограниченного набора «правил вывода», опирающихся, помимо этого содержания («семантической информации»), на общий фонд внеязыковых знаний («прагматической информации»).

6. Мотивировка (внутренняя форма) знака с точки зрения четырехуровневой модели понимания.

Означаемые образуют внутреннюю форму значений; значения - внутреннюю форму содержаний; содержания - внутреннюю форму смыслов.

7. Семантика понимается как наука, изучающая отношение языковых знаков к той смысловой информации, которая ими передается, а также само это отношение. Семантическая (внутренняя, смысловая, содержательная) сторона языкового знака противополагается его формальной (внешней) стороне (в устной речи - звуковой, фонетической, а в письменной речи - графической). В каком-то отношении семантика противоположна фонетике: если фонетика по возможности отвлекается от содержательного (внутреннего) аспекта языка и изучает лишь внешний (звуковой, фонетический или графический) аспект языка, то семантика, наоборот, по возможности отвлекается от внешнего (звукового или графического) аспекта языка и изучает его содержательный (смысловой, семантический) аспект.

7.1. Семантическая информация, передаваемая языковым знаком, определенным образом организована, поэтому можно выделять семантические единицы разной степени сложности и разной степени абстрактности (отвлеченности). 
7.2. Семантика сочетает семасиологический («пассивный») аспект рассмотрения (с позиций адресата речи, от форм к функциям) с ономасиологическим («активным») аспектом (с позиций автора речи, от функций к формам).

8. Отношения между экспонентами языковых знаков и их десигнатами (означаемыми, единицами уровня 4.1.1) изучаются, вообще говоря, не «собственно семантикой», но скорее другими дисциплинами - в первую очередь морфологией, синтаксисом и лексикологией.

Однако, по-видимому, целесообразно было бы для полноты картины допустить также понимание семантики в предельно широком смысле этого термина и, соответственно, выделять в ее составе также и такие области, которые для «собственно семантики» являются периферийными.

К числу таких периферийных зон семантики принадлежит, в частности, и «вырожденная» (тривиальная) семантика, изучающая отношения между экспонентами языковых знаков, с одной стороны, и их десигнатами (= означаемыми), т. е. единицами уровня 4.1.1, с другой стороны.

Тот раздел семантики, который занимается изучением этих отношений, может быть условно назван «тривиальной» (или «буквальной») семантикой.

Именно «тривиальная» семантика фиксируется при поморфемном (лексикограмматическом) «глоссировании» примеров в работах по типологии, когда лингвист пытается передать «буквальное» значение речевых отрезков на некотором изучаемом языке (для этого употребляется помета «букв.»).

В работах по автоматической обработке текстов обычен такой способ репрезентации, при котором исследователь отвлекается от феномена лексической и грамматической полисемии (как правило, не интересующей авторов подобных работ), но при этом обращает внимание на феномен лексической или грамматической омонимии («разрешение» которой считается важной и насущной, даже первоочередной, задачей автоматической обработки текстов - ср., в частности, «первоочередную» задачу «разрешения» синтаксической омонимии).

В обеих указанных ситуациях исследователь фактически прибегает к уровню такой «тривиальной» семантики.

Может возникнуть вопрос о том, принадлежит ли информация, фиксируемая при таком виде записи, к плану содержания языка вообще (а не к его плану выражения). Однако очевидно, что при переводе с одного языка на другой (например, с немецкого на русский) лингвистических работ по типологии и по автоматической обработке текстов широко используется тот прием, при котором запись «тривиальной семантики» (на немецком «метаязыке») не транскрибируется (или транслитерируется), а именно переводится в собственном смысле слова (т.е. для немецкого оригинала подыскивается подходящий наиболее понятный русский эквивалент).

Правда, если в качестве метаязыка тривиальной семантики используются пометы на основе квазилатинских аббревиатур («Sg», «Pl» и т. п.), то они не подвергаются обычному переводу, а воспроизводятся таким образом, как если бы они были универсально понятной транскрипцией. Именно поэтому для фиксации таких помет в начале XXI в., как известно, был разработан особый стандарт 
грамматической нотации, известный в качестве «Лейпцигских правил» [см., например: Касевич 2011: 214-221, с литературой]. Таким образом, для уровня «тривиальной семантики» можно считать разработанной «международную семантическую транскрипцию» ${ }^{5}$, в чем-то аналогичную «международной фонетической транскрипции», но относящуюся не к плану выражения языка, а к его плану содержания.

9. Наиболее разработана «инвентарная» семантика, т. е. семантика языковых знаков, составляющих «инвентарь» системы языка, изучающая соотношение между языковыми знаками и их (инвентарными) значениями, входящими в систему языка. К числу таких языковых знаков относятся морфема, слово, фразеологическая единица. Языковому инвентарю принадлежат единицы языка, хранимые в долговременной памяти: устойчивое словосочетание, устойчивая цитата; крылатые слова.

Важнейшими частями инвентарной семантики являются, с одной стороны, лексическая семантика (изучающая лексическое значение слова), лежащая на стыке семантики и лексикологии (она описывается в толковом словаре), и, с другой стороны, грамматическая семантика (изучающая смысловой аспект морфологической категории и частей речи), лежащая на стыке семантики и грамматики (она описывается в грамматике данного языка).

Характерной особенностью лингвистической семантики прошлого (до 1960-х гг., ставших для становления этой науки годами поистине революционного перелома $)^{6}$ было то, что «лексическая» и «грамматическая» семантика разрабатывались в отрыве друг от друга, т. е. не осмыслялись лингвистами как части некоторого единого целого. По-видимому, Ю.Д. Апресян был первым лингвистом (по меньшей мере одним из немногих первых лингвистов), который раньше других заметил и эксплицитно сформулировал сущность этого кардинального перелома в семантике как науке. Ср.: «Отличие современной лингвистической семантики от классической состоит прежде всего в том, что она интересуется не только и не столько значениями отдельных слов, сколько значениями целых предложений» [Апресян 1967: 8]; «Переход от описания значений отдельных слов к описанию значений целых высказываний обнажил до того скрытые механизмы равнозначного преобразования высказываний, почти не изучавшиеся традиционной семантикой, хотя они играют, по-видимому, центральную роль в речевом поведении человека» [Там же: 11]; «В традиционной семантике принято разграничение значений на лексические (выражаемые корневыми морфемами) и грамматические (выражаемые аффиксами, флексиями и т. п.). Из них только лексические рассматриваются в качестве полноправного объекта семантической теории,

${ }^{5}$ Ряд авторов ставит вопрос о том, насколько мыслима и насколько осуществима такая «семантическая транскрипция» (ср., например, работы [Падучева 1975: 558; Перцов 2006; Мельчук 2012]).

${ }^{6}$ См. обзоры семантических исследований, в которых подчеркивается отличие современного этапа семантических исследований от предшествующих ему «традиционных» подходов: [Апресян 1963: 102-149; 1967: 5-19; 1974: 6-15]. 
а исследование грамматических значений выводится за пределы семантики даже в тех случаях, когда означаемыми лексических морфем являются факты действительности (ср. значение числа). В соответствии с этим семантика довольно часто определяется как “наука о лексических значениях слов”. < ..> Очень простые факты показывают, что противопоставление лексических и грамматических значений в указанном здесь смысле далеко не всегда может быть наполнено реальным содержанием» [Там же: 16-17].

Понятие «традиционной» или «классической» семантики в работах Ю. Д. Апресяна 1960-х-1970-х гг. близко к тому, что в настоящей статье предлагается именовать «инвентарной» семантикой; а понятие «современной» семантики в работах Ю. Д. Апресяна 1960-х-1970-х гг. близко тому, что в настоящей статье предлагается именовать «интегральной» семантикой.

Отношения между означаемыми (десигнатами, уровень 4.1.1) и значениями (уровень 4.1.2) изучаются лексической (в том числе фразеологической) и грамматической (в том числе синтаксической) семантикой.

В предмете этих наук выделяются: «пассивный» аспект (инвентарно-семантическая амбивалентность, т. е. соответствие одного означаемого нескольким значениям - предмет семасиологии) и «активный» аспект (инвентарно-семантическая эквивалентность, т. е. соответствие одного значения нескольким означаемым предмет ономасиологии).

Инвентарная семантика сочетает семасиологический аспект (инвентарная семасиология) с ономасиологическим (инвентарная ономасиология) ${ }^{7}$.

Внутренняя сторона языкового знака (его «означаемое») может состоять из нескольких значений (в этом заключается явление «многозначности»). Разнообразие значений одного языкового знака (наряду со способами толкования лексического значения) изучается семасиологией [см., например: Звегинцев 1957; Шмелев $1964]$.

Вместе с тем одно и то же значение может выражаться разными языковыми знаками (в частности, лексическими синонимами). Разнообразие способов выражения одного значения разными языковыми знаками (в частности, с помощью различий во внутренней форме слова) изучается ономасиологией (в число задач которой входит составление идеографических словарей, словарей синонимов, словарей антонимов и т. п.).

Инвентарная семантика охватывает предметы ('я’, ‘ты', ‘человек', 'вещь', ‘тело’), определители (‘этот’, ‘тот же’, ‘другой’), количество ('один’, ‘два', ‘некоторые', 'все', 'много'), оценку ('хороший', 'плохой’), описание ('большой’, 'малый’), психику (или душу) ('думать', ‘знать', ‘хотеть', ‘чувствовать', ‘видеть', ‘слышать'), речь ('говорить', ‘слово’, ‘правда’), действия ('делать’), события ('происходить'), движение ('двигать(ся)', 'трогать'), бытие // существование ('быть'), обладание ('иметь'), жизнь ('жить'), смерть ('умереть'), время ('время',

7 О взаимоотношении этих двух аспектов см., например, [Кузнецова 1963; Бородина, Гак 1979]. 
‘когда', ‘сейчас', ‘до’, ‘после’, ‘долго', ‘недолго', ‘иногда', ‘момент’), пространство ('где', ‘место’, ‘здесь', ‘над’, ‘под’, ‘далеко', ‘близко’, ‘сторона', ‘вне', ‘внутри’), логические связки ('не', ‘возможно', ‘мочь', ‘потому что’, 'если’), интенсивность ('очень'), добавку ('еще'), таксономию ('разновидность'), частичность ('часть'), подобие ('похожий').

10. Важнейшим разделом современной семантики является «интегральная» ${ }^{8}$ (и в частности, в первую очередь, «сентенциальная») семантика, описывающая правила взаимодействия лексических и грамматических значений друг с другом в составе свободных речевых комбинаций инвентарных языковых знаков.

Такие речевые комбинации образуют «внеинвентарные» языковые единицы («свободное» словосочетание, «свободное» предложение, абзац, текст), производимые в ходе речевого акта (высказывания), содержание которых не равно простой сумме значений инвентарных языковых знаков.

Содержания и смыслы не являются инвентарными единицами (т.е. их нельзя задать перечнем; да и незачем это делать, если можно задать перечень тропов9). У содержания есть два аспекта — языковой и речевой: в языке содержание присуще внеинвентарным (экстраинвентарным) ${ }^{10}$ единицам, т. е. потенциальным (принципиально возможным) комбинациям единиц; в речи содержание присуще речевым реализациям этих комбинаций.

Отличие между значениями и содержаниями фактически обсуждается в связи с изучением языковых механизмов понимания речевых тропов, восстановлением некоторых «семантических эллипсисов» [см.: Леонтьева 1968], «зачеркиванием» избыточных смысловых компонентов, насыщением валентностей, наследованием и погашением презумпций. В отличие от механизмов четвертого (прагматического) этапа понимания механизмы данного (интегрально-семантического) этапа опираются лишь на те сведения, которые содержатся в данном речевом отрезке; отсюда и предлагаемый здесь выбор термина содержание.

Интегральная семантика изучает соотношение между содержанием речевого отрезка и значениями входящих в него языковых знаков.

8 Термин интегральный в этом смысле слова вошел в широкое употребление после работ Дж. Катца и Дж. Фодора (1963-1964), а в отечественной лингвистической традиции - благодаря появлению серии работ Ю.Д. Апресяна (особенно [Апресян 1986]).

9 Переносные значения как устойчивый факт языка следует отличать от переносного употребления слов в речи [Маслов 1975: 126-127]. «Число лексических значений (семантем) как единиц плана содержания языка, скорее всего, не может быть подсчитано. Есть семантемы устойчивые, воспроизводимые и, следовательно, достаточно легко инвентаризируемые. Есть семантемы-“однодневки”, и они не могут быть сосчитаны» [Сусов 2006: 106]; «... результирующих комбинаций признаков (т. е. “значений приставки” или “типов значения приставочных глаголов") так много, что невозможно себе представить, чтобы они входили в знание языка в виде списка. Очевидно, что говорящий обладает не списком, а механизмом, его порождающим» [Зализняк 2006: 304].

${ }_{10}$ Дихотомия инвентарных и экстраинвентарных единиц в принимаемом здесь понимании приблизительно соответствует тому, что в работах В.Б. Касевича именуется различием между «инвентарными» и «конструктивными» единицами [см., например: Касевич 2019: 73]. 
Отношения между значениями (уровень 4.1.2) и содержаниями (уровень 4.2.3) составляют предмет «интегральной» («сентенциальной», «контекстуальной») семантики.

Интегральная семантика может исходить из позиции адресата речи (слушающего или читателя) или из позиции автора речи (говорящего или пишущего). Соответственно, ее основными разделами являются, с одной стороны, «интерпретирующая» семантика, с другой стороны, «порождающая» семантика.

В ней тоже выделяются два аспекта - «рецептивный» (интегрально-семантическая амбивалентность, т. е. соответствие одного значения нескольким содержаниям - предмет «интерпретирующей» семантики) и «продуктивный» (интегрально-семантическая эквивалентность, т.е. соответствие одного содержания нескольким значениям - предмет «порождающей» семантики).

Термины интерпретирующая семантика и порождающая семантика в данной статье употребляются в несколько расширенном смысле, чем это принято обычно. Традиционно оба имеют более узкий объем: как известно, они соотносятся с двумя соперничавшими друг с другом подходами к семантике в американском генеративизме 1960- 1970-х гг. Если принять расширительное понимание этих терминов, то оказывается, что это соперничество между направлениями было лишено разумных оснований: ведь интерпретирующая и порождающая семантика имеют разные цели (моделирование понимания речи и моделирование порождения речи соответственно) и потому естественным образом дополняют друг друга. Спорить о том, какой тип моделей «нужнее», нет смысла, потому что для моделирования речевой деятельности как целого (включающего поведение адресата речи и поведение отправителя речи) одинаково необходимы оба этих вида моделей ${ }^{11}$. Фактически сторонники интерпретирующей семантики (в узком смысле слова) стихийно занимались построением моделей автоматического понимания (или «семантического анализа») $)^{12}$, а сторонники порождающей семантики (в узком смысле слова) стихийно занимались построением моделей автоматического семантического синтеза (и потому во многом перекликаются с тем подходом, который в отечественной традиции получил наименование «модели семантического синтеза»). Это обстоятельство служит оправданием для того расширительного понимания этих терминов, которое предлагается в настоящей статье.

Для того чтобы понять речевой отрезок (словосочетание или предложение), недостаточно просто суммировать значения тех языковых знаков, из которых оно составлено $^{13}$. Интерпретация предложения включает восстановление разнообразных речевых опущений (эллипсисов), понимания окказиональных речевых переносов (таких, как речевая метафора, метонимия, синекдоха, олицетворение и т. п.). Так, например, словосочетание таблетка от головы не равно простой сумме

${ }^{11}$ Ср. [Шаляпина 2007: 13-14], где обосновывается вывод о взаимной дополнительности конкурирующих подходов к моделированию речевой деятельности человека.

12 О таких моделях см. подробнее в книге Н.Н. Леонтьевой [2006].

${ }^{13} \mathrm{Cp}$.: «значение предложения складывается из значений лексем, грамматических значений словоформ и значений синтаксических конструкций» [Падучева 1974: 12]. 
словарных значений слов таблетка, от и голова, а передает содержание 'таблетка, помогающая лечить головную боль’) [см., например: Леонтьева 1967: 96-97; Апресян 1974: 80]. Интерпретирующая семантика, или модель семантического анализа (языкового понимания) речевых отрезков, показывает, каким образом из значений инвентарных единиц строится содержание тех речевых отрезков, из которых эти отрезки состоят ${ }^{14}$. Ее предмет - «механизм соединения семантических описаний отдельных компонентов текста - лексем, грамматических категорий, синтаксических конструкций — в семантическое описание текста в целом» [см.: Падучева 1975: 551].

Одно и то же речевое содержание может быть передано разными языковыми средствами (перифразами). Порождающая семантика, или модель семантического синтеза (вербализации содержания), показывает, каким образом подобрать такие выразительные средства языка ${ }^{15}$, чтобы с помощью комбинации этих «разноуровневых» средств выразить то содержание, которое автор речи хочет передать ее адресату.

11. Содержание предложения может отличаться от того речевого смысла, который автор высказывания вкладывает в свой речевой акт и хочет передать адресату $^{16}$. Так, например, предложение Здесь холодно может пониматься как просьба ('закрой форточку'); вопрос Где я возьму деньги? может пониматься как констатация факта ('у меня нет денег’) и т.п.

11.1. Для понимания «настоящего» (а не «буквального», т. е. «прямого») речевого («прагматического») смысла высказывания ${ }^{17}$ адресат должен опираться на некоторые «фоновые знания», а именно:

(а) на знание предшествующего речевого окружения, т. е. того контекста, который предшествовал данному высказыванию;

(б) на знание того предметного окружения, т. е. той текущей обстановки речи (= речевой ситуации), в которой делается данное высказывание;

(в) на знание правил речевого этикета, речевого общения, речевых стратегий и тактик, позволяющих говорящему употреблять разнообразные тропы и фигуры речи;

14 Таким образом, к этому разделу семантики относятся: «правила суммирования означаемых» [Мельчук 1974: 70-72], «законы взаимодействия значений» [Апресян 1974: 79-94], «правила взаимодействия значений» [Апресян 1980а: 68-87; 1980б; 2005; 2006], правила «семантической деривации» [Падучева 2004: 147-176], правила «композиции» («соединения значений частей в значение целого») [Падучева 1999; 2004: 113-143], правила «актуализации компонентов» [Падучева 2004: 94-101], правила заполнения семантических валентностей и «сфер действия» [Богуславский 1996].

15 Эти единицы можно назвать средствами выразительности (синтаксическими, фразеологическими, лексическими, словообразовательными, морфологическими и фонетическими).

16 О различии между «планом содержания предложения» и его «речевым смыслом» см. [Бондарко 1978: 95].

17 Ср.: «Объект, с которым должна иметь дело семантика, - это не только семантическое представление предложения, но и семантико-прагматическое представление предложения, включенного в речевой акт» [Падучева 1985: 4]. 
(г) на совокупность фоновых энциклопедических знаний о мире, общих для обоих собеседников.

11.2. Таким образом, есть четыре источника фоновых знаний (образно выражаясь, четыре «корзины» прагматической информации):

(а) «контекстуальная (анафорическая) информация» - смысл «антецедентов», т. е. речевых отрезков, входящих в состав связного текста (дискурса), который является объемлющим для интерпретируемого речевого отрезка и при этом предшествуют данному речевому отрезку;

(б) «конситуативная (дейктическая) информация» - сведения о параметрах речевого акта: состав коммуникантов; обстоятельства протекания (момент, место и др.); «общее поле зрения участников»; иногда она выражена невербальными средствами (жестами, мимикой и т.п.) $)^{18}$;

(в) «этикетная информация» (// «коммуникативная компетенция») - ограниченный набор (инвентарь) постулатов коммуникации, т.е. «конверсационных» правил, владение которыми принято в социуме, охватывающем данный акт общения;

(г) «энциклопедическая информация» (// «предметная компетенция»), т. е. сведения о мире, входящие в общий фонд знаний (базу данных), разделяемый коммуникантами.

Вывод смысла из содержания с опорой на энциклопедическую информацию может быть проиллюстрирован примерами, обсуждаемыми в ряде работ Ю.Д. Апресяна: «Анализ языковых выражений в процессе общения позволяет нам обнаружить еще один род содержания, которое они могут иметь, - так называемое прагматическое значение, под которым понимается внеязыковая реакция слушающего, вызываемая данным языковым стимулом (языковым выражением). Пусть нам сообщили, что некто проплыл 100 метров за 45 секунд (пример Ч. Фриза). Профан может реагировать на это сообщение пожатием плеч, а заинтересованный специалист - выражением бурной радости, так как он понимает, что пловец установил феноменальный мировой рекорд. Денотативное, сигнификативное и синтаксическое значение указанного предложения для всех участников общения одно и то же, но для разных участников оно имеет разные прагматические значения. <..> Прагматические значения образуют предмет прагматики...» [Апресян 1967: 6-7]; «Подчеркнем, что здесь имеются в виду умения, основанные на владении чисто языковой (словарной и грамматической), а не энциклопедической информацией. Текст Он пропльл 100 метров кролем за 45 секунд для всякого носителя русского языка значит: 'Плывя стилем “кроль”, он покрыл расстояние в сто метров и затратил на это 45 секунд’. Для тех, кто знает не только русский язык, но и таблицу мировых достижений в плавании (элемент энциклопедической, а не языковой информации), то же самое предложение может оказаться гораздо содержательнее. Оно может быть воспринято как сенсационное сообщение о феноменальном мировом рекорде, как напоминание о безграничных физических возможностях человека

${ }^{18}$ Ср. описание ситуативного эллипсиса у С.Н. Цейтлин. 
и т. п. Достаточно знать только грамматику языка и словарные значения слов, чтобы построить перифразы Стометровую дистанцию (стометровку) он пропльл кролем за 45 секунд, На сто метров кролем у него ушло 45 секунд, Стометровку он прошел кролем за 45 секунд, Он затратил 45 секунд на то, чтобы пройти кролем расстояние в 100 метров, Стометровку он пропльл кролем за 3/4 минуты и очень многие другие. К услугам знатока спорта будут и совершенно иные возможности перифразирования: Кратчайшую олимпийскую дистанцию он пропльл кролем за 45 секунд, На стометровой дистанции кролем он на 10 секунд улучиил прежний мировой рекорд и т. д. Если человек владеет только языковой информацией, он не сумеет сказать, являются ли семантически связными тексты: Он пропльл 100 метров кролем за 45 секунд, установив, таким образом, феноменальный мировой рекорд и Он пропльл 100 метров кролем за 45 секунд, едва выполнив, таким образом, норму третьего разряда. Если же человек владеет и соответствующей энциклопедической информацией, первое предложение будет для него семантически связно, хотя и неправдоподобно, а второе - несвязно или ложно» [Апресян 1974: 13].

Идея вывода смысла из содержания с опорой на энциклопедические знания до известной степени перекликается с семантической теорией информации, предлагавшейся в свое время в работах Ю.А. Шрейдера [см.: Шрейдер 1965; 1967]: ценность информации, передаваемой от ее источника к ее приемнику в ходе получения некоторого сообщения, определяется как мера изменения так называемого тезауруса (понимаемого как набор сведений, составляющих энциклопедическую информацию, хранимую в долговременной памяти) этого приемника в результате получения данного сообщения.

11.3. Знания типа (а) и (б) хранит «кратковременная», а типа (в) и (г) — «долговременная» память.

11.4. Соотношение содержания речевого отрезка с его речевым смыслом предмет лингвистической прагматики (или семантики речевых актов), составляющей важную часть современной лингвистической семантики ${ }^{19}$.

Отношения между содержаниями (уровень 4.2.3) и смыслами (уровень 4.2.4) составляют предмет прагматики.

Заслуживает особого внимания тот факт, что Ю. Д. Апресян в работе 1974 г. отмечал (со ссылкой на концепцию Кембриджского лингвистического кружка и на работу Ю.С. Мартемьянова 1964 г.), что можно выделять по крайней мере два уровня понимания. По словам Ю.Д. Апресяна, «можно говорить о понимании в слабом и в сильном смысле. Понимание в слабом смысле (локальное, первый этап анализа) - это умение извлечь из каждого предложения содержащуюся в нем информацию. Понимание в сильном смысле (глобальное, второй этап анализа) - это умение построить на основании извлеченной из данного

19 При этом, вообще говоря, правила прагматики носят не конвенциональный, а универсальный характер, что отличает их от правил интегральной (не говоря уже об инвентарной) семантики [см.: Булыгина 1981]. 
предложения информации правдоподобную гипотезу о возможном содержании следующего за ним предложения» [Апресян 1974: 40]. Далее отмечается, что «имеет место понимание текста, если мы можем извлечь из каждого предложения текста картину описываемой этим предложением ситуации. Но существует и понимание в более глубоком смысле. На основании уже усвоенной семантической информации, поступившей из осмотренной или прослушанной части текста, читатель (слушатель и т.п.) строит правдоподобные гипотезы о возможном содержании предшествующей и последующей частей текста. Мера подтверждения возникающих при восприятии текста гипотез такого рода и есть мера его понимания. <..> Основанием для построения гипотез является 1) знание свойств участников “текущей” ситуации, 2) знание импликативных законов, связывающих данные свойства с другими свойствами. Если, например, в данном месте текста сказано: На поляне горел костер, мы можем заключить, что а) некое лицо раньше зажгло его с определенной целью, например с целью приготовить пищу; б) что на поляне в непосредственной близости от костра относительно светло и можно видеть окружающие предметы, относительно тепло и можно согреться и т. п. Поэтому, осмотрев предшествующий и последующий куски текста, мы не удивимся, если найдем в них упоминание лица, зажегшего костер, или упоминание приготовленной пищи, или упоминание жмущихся к костру продрогших людей и т. д.» [Там же].

То, что в приведенной цитате Ю.Д. Апресян именует локальным пониманием текста (или пониманием в слабом смысле), приблизительно соответствует тому, что выше названо пониманием содержания текста (в отличие от понимания «смысла» данного текста) и составляет часть «интегральной» семантики. А то, что Ю. Д. Апресян обозначает как глобальное понимание текста (или понимание в сильном смысле), приблизительно соответствует тому, что выше названо пониманием «смысла» данного текста.

11.5. В составе лингвистической прагматики (которую порой также называют «глубинной семантикой» [см., например: Перцова 1975; 1977a; 1977б; 1977в; $1980 \mathrm{a} ; 19806])$ также можно выделить два направления, соответствующие различию между психологическими установками автора речи и ее адресата: лингвистическую риторику (образно говоря, теорию «прагматического синтеза») vs. лингвистическую герменевтику (образно говоря, теорию «прагматического анализа»).

Лингвистическая риторика изучает разнообразие способов речевого «иносказания», т. е. способов косвенного (переносного) выражения речевого смысла с помощью речевых отрезков с разным содержанием. Основной ее предмет - прагматическая эквивалентность речевых отрезков, выражающих один и тот же смысл с помощью разных содержаний.

Лингвистическая герменевтика изучает разнообразие переносных смыслов, т. е. переносных (косвенных) способов интерпретации одного и того же содержания речевого отрезка. Основной ее предмет - многообразие интерпретаций (прочтений), т. е. прагматическая амбивалентность речевых отрезков, имеющих одно и то же содержание, но потенциально допускающих разные смыслы. 
Соотношение аспектов семиозиса и разделов семантики, выделяемых в соответствии с предлагаемой классификацией, можно схематически представить следующей таблицей.

таблица

\begin{tabular}{|l|l|l|l|l|l|}
\hline $\begin{array}{l}\text { Аспекты семи- } \\
\text { озиса }\end{array}$ & $\begin{array}{l}\text { Моделируемые } \\
\text { аспекты асимм-- } \\
\text { трии языковых } \\
\text { знаков }\end{array}$ & $\begin{array}{l}\text { Тривиальная } \\
\text { семантика }\end{array}$ & $\begin{array}{l}\text { Инвентарная } \\
\text { семантика }\end{array}$ & $\begin{array}{l}\text { Интеграль- } \\
\text { ная семан- } \\
\text { тика }\end{array}$ & Прагматика \\
\hline $\begin{array}{l}\text { Понимание } \\
\text { (речевоспри- } \\
\text { ятие) }\end{array}$ & $\begin{array}{l}\text { Амбивалент- } \\
\text { ность }\end{array}$ & $\begin{array}{l}\text { Тривиальная } \\
\text { семасиоло- } \\
\text { гия }\end{array}$ & $\begin{array}{l}\text { (Инвентарная) } \\
\text { семасиология }\end{array}$ & $\begin{array}{l}\text { Интерпре- } \\
\text { тирующая } \\
\text { семантика }\end{array}$ & $\begin{array}{l}\text { Герменев- } \\
\text { тика }\end{array}$ \\
\hline $\begin{array}{l}\text { Вербализация } \\
\text { (речепорожде- } \\
\text { ние) }\end{array}$ & Эквивалентность & $\begin{array}{l}\text { Тривиальная } \\
\text { ономасиоло- } \\
\text { гия }\end{array}$ & $\begin{array}{l}\text { (Инвентарная) } \\
\text { ономасиология }\end{array}$ & $\begin{array}{l}\text { Порождаю- } \\
\text { щая семан- } \\
\text { тика }\end{array}$ & Риторика \\
\hline
\end{tabular}

\section{Литература}

Апресян Ю. Д. Современные методы изучения значений и некоторые проблемы структурной лингвистики // Проблемы структурной лингвистики / ред. С.К. Шаумян. М. : Изд-во АН СССР, 1963. С. 102-149.

Апресян Ю.Д. Экспериментальное исследование семантики русского глагола. М. : Наука, 1967. 251 с.

Апресян Ю.Д. Лексическая семантика (синонимические средства языка). М. : Наука, 1974. 367 с.

Апресян Ю. Д. Типы информации для поверхностно-семантического компонента модели «Смысл $\Leftrightarrow$ Текст». Wien : WSA, 1980a. 119 с.

Апресян Ю. Д. К формальной модели семантики: правила взаимодействия значений // Представление знаний и моделирование процессов понимания / под ред. А. С. Нариньяни. Новосибирск : ВЦ СОАН, 1980б. С. 48-65.

Апресян Ю.Д. Интегральное описание языка и толковый словарь // Вопросы языкознания. 1986. № 2. С. 57-70.

Апресян Ю.Д. Правила взаимодействия значений и словарь // Русский язык в научном освещении. 2005. № 9. С. 7-45.

Апресян Ю.Д. Правила взаимодействия значений // Апресян В.Ю., Аnpeсян Ю. Д., Бабаева Е. Э., Богуславская О. Ю., Иомдин Б. Л., Крылова Т. В., Левонтина И.Б., Санников А. В., Урысон Е. В. Языковая картина мира и системная лексикография / отв. ред Ю. Д. Апресян. М. : Языки славянских культур, 2006. С. 110-144.

Богуславский И.М. Сфера действия лексических единиц. М. : Языки русской культуры, 1996. 460 с.

Бондарко А. В. Грамматическое значение и смысл. Л. : Наука, 1978. 176 с.

Бородина М.A., Гак В.Г. К типологии и методике историко-семантических исследований. Л. : Наука, 1979. 232 с. 
Бульгина Т. В. О границах и содержании прагматики // Известия АН СССР. Серия литературы и языка. 1981. Т. 40. № 4. С. 333-342.

Зализняк Анна A. Многозначность в языке и способы ее представления. М. : Языки славянских культур, 2006. 672 с.

Звегинцев В. А. Семасиология. М. : Изд-во МГУ, 1957. 322 с.

Звегинцеев B. A. Смысл и значение // Теоретические и экспериментальные исследования в области структурной и прикладной лингвистики / ред. В. А. Звегинцева. М. : Изд-во МГУ, 1973. С. 92-97.

Касевич В. Б. Введение в языкознание. М. ; СПб. : Академия, 2011. 230 с.

Касевич В.Б. Проблемы семантики. СПб. : Изд-во СПбГУ, 2019. 304 с.

Кобозева И. М. Лингвистическая семантика. М. : УРСС, 2000а. 352 с.

Кобозева И. М. Две ипостаси содержания речи: значение и смысл // Язык о языке / под ред. Н. Д. Арутюновой. М. : Языки русской культуры, 2000б. С. 303-359.

Кузнеиова А.И. Понятие семантической системы языка и методы ее исследования (Из истории разработки данной проблемы в современном зарубежном языкознании). М. : Изд-во МГУ, 1963. 60 с.

Леонтьева Н.Н. Устранение некоторых видов избыточной информации в естественном языке // Машинный перевод и прикладная лингвистика. 1967. Вып. 10. C. 93-98.

Леонтьева Н. Н. Семантический анализ и смысловая полнота текста : автореф. дис. ... канд. филол. наук / Моск. гос. ун-т. М., 1968. 20 с.

Леонтьева Н.Н. Автоматическое понимание текстов: Системы, модели, ресурсы. М. : Академия, 2006. 304 с.

Маслов Ю. С. Введение в языкознание. М. : Высшая школа, 1975. 327 с.

Мельчук И. А. Опыт теории лингвистических моделей «Смысл $\Leftrightarrow$ Текст». Ч. 1 : Семантика. Синтаксис. М. : Наука, 1974. 314 с.

Мельчук И.А. От смысла — к тексту. М. : Наука ; Языки славянских культур, 2012. $174 \mathrm{c}$.

Падучева E. В. О семантике синтаксиса. Материалы к трансформационной грамматике русского языка. М. : Наука, 1974. 291 с.

Падучева E. B. Некоторые проблемы моделирования соответствия между текстом и смыслом в языке // Известия АН СССР. Серия литературы и языка. 1975. Т. 34. № 6. С. 548-559.

Падучева E. В. Высказывание и его соотнесенность с действительностью: референциальные аспекты семантики местоимений. М. : Наука, 1985. 294 с.

Падучева E. В. Принцип композиционности в неформальной семантике // Вопросы языкознания. 1999. №6. С. 3-24.

Падучева E. В. Динамические модели в семантике лексики. М. : Языки славянской культуры, 2004. 608 с.

Перияов Н.В. К проблеме построения семантического метаязыка // Компьютерная лингвистика и интеллектуальные технологии : труды Междунар. конф. «Диалог - 2006» (Бекасово, 31 мая - 4 июня 2006 г.) / под ред. Н. И. Лауфер, А. С. Нариньяни, В. П. Селегея. М. : Изд-во РГГУ, 2006. С. 419-425. 
Периова Н. Н. Об уровнях понимания текста на естественном языке // Семантические вопросы искусственного интеллекта. Киев : Знание, 1975. С. 19-20.

Периова Н. Н. К проблеме представления содержания текста // ИРЯ АН СССР. Проблемная группа по экспериментальной и прикладной лингвистике. Предварительные публикации. 1977а. Вып. 91. С. 22-35.

Периова Н.Н. Понимание естественного языка как активный процесс // ИРЯ АН СССР. Проблемная группа по экспериментальной и прикладной лингвистике. Предварительные публикации. 1977б. Вып. 93. С. 39-45.

Периова Н. Н. К проблеме моделирования понимания текста : дис. ... канд. филол. наук / Моск. гос. ун-т. М., 1977в. 181 с.

Периова Н. Н. О понимании нестандартного текста // Семиотика и информатика. 1980а. Вып. 15. С. 156-168.

Периова Н. Н. К построению глубинно-семантического компонента модели понимания текста // Проблемы вычислительной лингвистики и автоматической обработки текста на естественном языке. М. : Изд-во МГУ, 1980б. С. 3-50.

Слюсарева Н.А. Смысл как экстралингвистическое явление // Как подготовить интересный урок иностранного языка / под ред. Т. А. Дегтеревой. М. : Изд-во ВПШ, 1963. С. 185-199.

Сусов И. П. Введение в языкознание. М. : Восток-Запад, 2006. 327 с.

Шаляпина 3. М. Трехмерная стратификационная модель языка и его функционирования. М. : Восточная литература, 2007. 480 c.

Швейщер А. Д. Перевод и лингвистика. М. : Наука, 1988. 215 с.

Шмелев Д. Н. Очерки по семасиологии русского языка. М. : Наука, 1964. 248 с.

Шрейдер Ю. А. Об одной модели семантической теории информации // Проблемы кибернетики. 1965. Вып. 13. С. 233-240.

Шрейдер Ю.А. О семантических аспектах теории информации // Информация и кибернетика. 1967. №5. С. 22-37.

\author{
S. A. Krylov \\ Institute of Oriental Studies (Russian Academy of Sciences) \\ (Russia, Moscow) \\ krylov-58@mail.ru
}

\title{
ON THE QUESTION OF DISTINGUISHING SURFACE AND DEEP SEMANTICS
}

The purpose of this article is to preliminarily outline a certain approach in which there are 4 "levels" of depth in semantics, and also to try to classify linguistic disciplines (primarily sections of modern semantics) in accordance with this "4-level" approach. The signifier and the signified are directly related to each other. Their one-to-one correspondence is violated only with morphological equivalence (polymorphism, that is, 
homosemia and doubleness) and ambivalence (homonymy). The meaning and sense are connected by an "asymmetric connection," which includes, in addition to direct nomination (and the main meaning), deviations from it: namely, inventory-semantic equivalence (language synonymy) and inventory-semantic ambivalence (language polysemy). The meanings and signifiers (as well as the signified) belong to the language system, they are stored in long-term memory, their number can be calculated. They can be listed in the inventory (lexicon or grammar). The contents and meanings belong to speech, they are stored in short-term memory, it is impossible to list them, but they are formed according to certain integral-semantic and pragmatic rules, therefore they can be calculated. Such sections of semantics are schematically distinguished, they are: trivial (it studies the relationship between the signifier and the signified), inventory (it studies the relationship between the signified and the meaning), integral (it studies the relationship between the meaning and content) and pragmatic (it studies the relationship between content and meaning; = pragmatics). Regardless of this division, the semantics are divided into the semantics of the speaker and the semantics of the listener; therefore, semasiology vs. onomasiology, inside the integral - interpretive vs. generative semantics, inside the pragmatic - hermeneutics and rhetoric. Semasiology, interpreting semantics (= model of semantic analysis) and hermeneutics (= model of pragmatic analysis) are engaged in modeling understanding (speech perception). Onomasiology, generating semantics (= model of semantic synthesis) and rhetoric (= model of pragmatic synthesis), are engaged in the modeling of speaking (speech production).

Key words: semantics, meaning, signified, meaning, content, pragmatics, analysis, synthesis, semasiology, onomasiology.

\section{Acknowledgements}

The research was partially carried out within the projects 1704 00594-ОГН ОГН-А "Automatic dictionary RUSLAN: updated concept, new vocabulary", 1801200650 A "Semantic categories in the grammatical structure of the Russian language", 17-2902305 and 17-29-09158 офи_м "Creating a corpus of official business texts of the Russian language (RLOBTC)" supported by the Russian Foundation for Basic Research.

\section{References}

Apresyan Yu.D. [Modern methods of studying meanings and some problems of structural linguistics]. Problemy strukturnoi lingvistiki [Problems of structural linguistics]. S.K. Shaumyan (Ed.). Moscow, AS USSR Publ., 1963, pp. 102-149. (In Russ.)

Apresyan Yu.D. Eksperimental'noe issledovanie semantiki russkogo glagola [An experimental study of the semantics of the Russian verb]. Moscow, Nauka Publ., 1967. $251 \mathrm{p}$.

Apresyan Yu.D. Leksicheskaya semantika (sinonimicheskie sredstva yazyka) [Lexical semantics (synonymous means of language)]. Moscow, Nauka Publ., 1974. 367 p. 
Apresyan Yu.D. Tipy informatsii dlya poverkhnostno-semanticheskogo komponenta modeli «Smysl $\Leftrightarrow$ Tekst» [Types of information for the surface-semantic component of the "Meaning $\Leftrightarrow$ Text" model]. Wien, WSA Publ., 1980a. 119 p.

Apresyan Yu.D. [On the formal model of semantics: rules for the interaction of meanings]. Predstavlenie znanii i modelirovanie protsessov ponimaniya [Representation of knowledge and modeling of understanding processes]. A. S. Narin'yani (Ed.). Novosibirsk, VTs SOAN Publ., 1980b, pp. 48-65. (In Russ.)

Apresyan Yu.D. [Integral description of language and explanatory dictionary]. Voprosy yazykoznaniya, 1986, no. 2, pp. 57-70. (In Russ.)

Apresyan Yu.D. [Rules for the interaction of meanings and vocabulary]. Russkii yazyk v nauchnom osveshchenii, 2005, no. 9, pp. 7-45. (In Russ.)

Apresyan Yu.D. [Rules for the interaction of values]. Apresyan V.Yu., Apresyan Yu.D., Babaeva E.E., Boguslavskaya O.Yu., Iomdin B.L., Krylova T.V., Levontina I.B., Sannikov A.V., Uryson E.V. Yazykovaya kartina mira i sistemnaya leksikografiya [The Linguistic picture of the world and systemic lexicography]. Yu.D. Apresyan (Ed.). Moscow, Yazyki slavyanskikh kul'tur Publ., 2006, pp. 110-144. (In Russ.)

Boguslavskii I. M. Sfera deistviya leksicheskikh edinits [Scope of lexical units]. Moscow, Yazyki russkoi kul'tury Publ., 1996. 460 p.

Bondarko A.V. Grammaticheskoe znachenie i smysl [Grammatical meaning and sense]. Leningrad, Nauka Publ., 1978. 176 p.

Borodina M.A., Gak V.G. K tipologii i metodike istoriko-semanticheskikh issledovanii [On typology and methodology of historical and semantic research]. Leningrad, Nauka Publ., 1979. 232 p.

Bulygina T. V. [On the boundaries and content of pragmatics]. Izvestiya AN SSSR. Seriya literatury i yazyka, 1981, no. 4 (40), pp. 333-342. (In Russ.)

Kasevich V.B. Vvedenie v yazykoznanie [Introduction to Linguistics]. Moscow, St Petersburg, Akademiya Publ., 2011. 230 p.

Kasevich V. B. Problemy semantiki [Problems of semantics]. St Petersburg, St Petersburg St. Univ. Publ., 2019. 304 p.

Kobozeva I. M. Lingvisticheskaya semantika [Linguistic semantics]. Moscow, URSS Publ., 2000a. 352 p.

Kobozeva I. M. [Two hypostases of the content of speech: meaning and sense]. Yazyk o yazyke [Language about the language]. N. D. Arutyunova (Ed.). Moscow, Yazyki russkoi kul'tury Publ., 2000b, pp. 303-359. (In Russ.)

Kuznetsova A. I. Ponyatie semanticheskoi sistemy yazyka i metody ee issledovaniya (Iz istorii razrabotki dannoi problemy $v$ sovremennom zarubezhnom yazykoznanii) [The concept of the semantic system of language and methods of its research (From the history of the development of this problem in modern foreign linguistics)]. Moscow, Moscow St. Univ. Publ., 1963. 60 p.

Leont'eva H.H. [The Elimination of some types of redundant information in a natural language]. Mashinnyi perevod i prikladnaya lingvistika, 1967, no. 10, pp. 93-98. (In Russ.) 
Leont'eva H.H. Semanticheskii analiz i smyslovaya polnota teksta: avtoref. dis. ... kand. filol. nauk [Semantic analysis and semantic completeness of the text. Dr. phil. sci. diss. Summary]. Moscow, 1968. 20 p.

Leont'eva H.H. Avtomaticheskoe ponimanie tekstov: Sistemy, modeli, resursy [Automatic understanding of texts: Systems, models, resources]. Moscow, Akademiya Publ., 2006. $304 \mathrm{p}$.

Maslov Yu.S. Vvedenie v yazykoznanie [Introduction to Linguistics]. Moscow, Vysshaya shkola Publ., 1975. 327 p.

Mel'chuk I. A. Opyt teorii lingvisticheskikh modelei «Smysl $\Leftrightarrow$ Tekst». Ch. 1: Semantika. Sintaksis [Applying the theory of linguistic models "Meaning $\Leftrightarrow$ Text". Part 1. Semantics. Syntax]. Moscow, Nauka Publ., 1974. 314 p.

Mel'chuk I. A. Ot smysla $-k$ tekstu [From meaning to text]. Moscow, Nauka Publ., Yazyki slavyanskikh kul'tur Publ., 2012. 174 p.

Paducheva E. V. O semantike sintaksisa. Materialy k transformatsionnoi grammatike russkogo yazyka [On the semantics of syntax. Materials for the transformational grammar of the Russian language]. Moscow, Nauka Publ., 1974. 291 p.

Paducheva E. V. [Some problems of modeling the correspondence between text and meaning in the language]. Izvestiya AN SSSR. Seriya literatury i yazyka, 1975, no. 6 (34), pp. 548-559. (In Russ.)

Paducheva E. V. Vyskazyvanie i ego sootnesennost's deistvitel'nost'yu: referentsial'nye aspekty semantiki mestoimenii [The utterance and its correlation with reality: referential aspects of the semantics of pronouns]. Moscow, Nauka Publ., 1985. 294 p.

Paducheva E. V. [The principle of compositionality in informal semantics]. Voprosy yazykoznaniya, 1999, no. 6, pp. 3-24. (In Russ.)

Paducheva E. V. Dinamicheskie modeli v semantike leksiki [Dynamic models in the semantics of vocabulary]. Moscow, Yazyki slavyanskoi kul'tury Publ., 2004. 608 p.

Pertsov N.V. [On the problem of constructing a semantic metalanguage]. Komp'yuternaya lingvistika i intellektual'nye tekhnologii: trudy Mezhdunar. konf. «Dialog - 2006» (Bekasovo, 31 maya - 4 iyunya 2006 g.) [Computer Linguistics and Intelligent Technologies: Proceedings of the International Conference "Dialogue - 2006" (Bekasovo, May 31 - June 4, 2006)]. N. I. Laufer, A. C. Narin'yani, V.P. Selegey (Eds.). Moscow, Rus. St. Univ. for the Humanities Publ., 2006, pp. 419-425. (In Russ.)

Pertsova N.N. [About the levels of understanding of a text in a natural language]. Semanticheskie voprosy iskusstvennogo intellekta [Semantic questions of artificial intelligence]. Kiev, Znanie Publ., 1975, pp. 19-20. (In Russ.)

Pertsova N. N. [On the Problem of Presenting the Content of a Text]. IRYa AN SSSR. Problemnaya gruppa po eksperimental'noi i prikladnoi lingvistike. Predvaritel'nye publikatsii [RLI AS USSR. The problem group for experimental and applied linguistics. Preliminary publications], 1977a, iss. 91, pp. 22-35. (In Russ.)

Pertsova N.N. [The Understanding of the natural language as an active process]. IRYa AN SSSR. Problemnaya gruppa po eksperimental'noi i prikladnoi lingvistike. Predvaritel'nye publikatsii [RLI AS USSR. The problem group for experimental and applied linguistics. Preliminary publications], 1977b, iss. 93, pp. 39-45. 
Pertsova N.N. K probleme modelirovaniya ponimaniya teksta: dis. ... kand. filol. nauk [On the problem of modeling understanding of a text. Dr. phil. sci. diss.]. Moscow, 1977c. 181 p.

Pertsova N. N. [On the understanding of a non-standard text]. Semiotika i informatika, 1980a, no. 15, pp. 156-168. (In Russ.)

Pertsova N.N. [Towards the construction of a deep-semantic component of a text understanding model]. Problemy vychislitel'noi lingvistiki $i$ avtomaticheskoi obrabotki teksta na estestvennom yazyke [Problems of Computational Linguistics and Automatic Processing of Text in a Natural Language]. Moscow, Moscow St. Univ. Publ., 1980b, pp. 3-50. (In Russ.)

Shalyapina Z.M. Trekhmernaya stratifikatsionnaya model' yazyka i ego funktsionirovaniya [The Three-dimensional stratification model of the language and its functioning]. Moscow, Vostochnaya literatura Publ., 2007. 480 p.

Shmelev D. N. Ocherki po semasiologii russkogo yazyka [Essays on the semasiology of the Russian language]. Moscow, Nauka Publ., 1964. 248 p.

Shreider Yu.A. [On a model of the semantic theory of information]. Problemy kibernetiki, 1965, no. 13, pp. 233-240. (In Russ.)

Shreider Yu.A. [On the semantic aspects of information theory]. Informatsiya i kibernetika, 1967, no. 5, pp. 22-37. (In Russ.)

Shveitser A.D. Perevod i lingvistika [Translation and Linguistics]. Moscow, Nauka Publ., 1988. 215 p.

Slyusareva N.A. [Sense as an extralinguistic phenomenon]. Kak podgotovit' interesnyi urok inostrannogo yazyka [How to prepare an interesting lesson in a foreign language]. T. A. Degtereva (Ed.). Moscow, Higher Communist Party School Publ., 1963, pp. 185-199. (In Russ.)

Susov I.P. Vvedenie v yazykoznanie [Introduction to Linguistics]. Moscow, VostokZapad Publ., 2006. 327 p.

Zaliznyak Anna A. Mnogoznachnost'v yazyke i sposoby ee predstavleniya [Ambiguity in the language and methods of its presentation]. Moscow, Yazyki slavyanskikh kul'tur Publ., 2006. 672 p.

Zvegintsev V.A. [Sense and meaning]. Teoreticheskie i eksperimental'nye issledovaniya $v$ oblasti strukturnoi i prikladnoi lingvistiki [Theoretical and experimental studies in the field of structural and applied linguistics]. V.A. Zvegintsev (Ed.). Moscow, Moscow St. Univ. Publ., 1973, pp. 92-97. (In Russ.)

Zvegintsev V.A. Semasiologiya [Semasiology]. Moscow, Moscow St. Univ. Publ., 1957. $322 \mathrm{p}$. 